\title{
Distribution and Fractionation of Heavy Metals in Sediments of Karra River, Hetauda, Nepal
}

\author{
Sadhana Pradhanang \\ Central Department of Environmental Science \\ Tribhuvan University, Kathmandu, Nepal \\ E-mail: sadhana.pradhanang@gmail.com
}

\begin{abstract}
A five-step sequential extraction procedure was applied for the determination of the distribution of four elements (Cr, Mn, Fe, and Ni) in sediment of the Karra River. Sediment samples were collected from 16 different sites in the Karra River (upstream, industrial belt, downstream). The distribution of trace metals among exchangeable, carbonate, reducible, oxidizable and residual fractions were determined. The total concentration of metals varies in the range of $\mathrm{Cr} 72-4339.54 \mathrm{mg} \mathrm{kg}{ }^{-1}$, Mn 22-411.93 mg kg-1, Fe 2967.23-32423.0 mg kg-1 and Ni 31.70-180.74 mg kg-1. The accuracy evaluated by comparing total trace metal concentrations with the sum of the five individual fractions proved to be satisfactory. The chemical speciation of $\mathrm{Cr}, \mathrm{Mn}, \mathrm{Fe}$, and $\mathrm{Ni}$ in most sampling stations were in the order of residual $>$ reducible $>$ oxidazable $>$ carbonate $>$ exchangeable. Fractionation analysis showed that dominant metals are in residual fraction. The highest metal concentrations were observed at the most polluted sites of the industrial belt. High concentration of chromium was found in the Fe-Mn oxide and organic fraction in some of the sites of industrial belt.
\end{abstract}

Keywords: Sequential extraction, distribution, sediment, Karra River, Trace metal.

\section{INTRODUCTION}

Sediments are important carriers of heavy metals in the hydrological cycle and because metals are partitioned with the surrounding waters, they reflect the quality of an aquatic system (Chatterjee et al. 2007). Heavy metals are one of the most common pollutants in aquatic environments from either natural source, such as geologic weathering or anthropogenic sources such as industrial, agricultural, municipal and residential waste products (Demirak, 2006). Metals that do not remain soluble in water, gets adsorbed and accumulated on bottom sediments (Jain et al. 2005). Heavy metals can be either adsorbed into riverine sediments or accumulated in benthic organisms, sometimes at toxic level (D e s s a i and Nayak, 2009; Singh et al. 2005). Therefore, sediment serves as the carrier and reservoir of the heavy metals and reflects the quality of the system (Chapman \& Wang, 1999). Metals cannot always be permanently fixed by sediments. Some of the sediment-bound metals may remobilize and can be released back to the waters via variation of environmental conditions such as acidification, redox potential, and chelation, etc., and impose adverse effects on living organisms (Sutherland \& Tact., 2007; Rath, 2009). Thus the mobility of metals in the environment depends on their chemical forms or type of the binding of the element. Heavy metals are of high ecological significance since they are not removed from water as a result of self-purification and enter the food chain (Loska \& Wiechula, 2003). It is known that total heavy metal content itself is not good measurement of bioavailability and not a very useful method to determine the potential risks from sediment contamination. The heavy metal contaminant strongly depends on the metals speciation, mobility and bio-availability, this approach is theoretically very useful for site assessment and risk analysis (Howard \& Shu, 1996). The method of fractionation of trace metals in sediments are based on sequential extraction procedures. Sequential extraction is used to determine geochemical partitioning of heavy metals in soil, sediments and sludge (Howard \& Shu, 1996). So it is widely used to estimate the amounts and proportions of metals in soil or sediment and to predict bio-availability and metal leaching (Jalali \& Khanlari, 2008). A sequential extraction method proposed by Tessier et al. (1979) and Kersten and Forstner (1986).

The modified sequential extraction procedure is introduced to determine the five fractions of metals in the sediment and five step Tessier et al. (1979) schemes are most widely accepted. The major mechanism of accumulation of heavy metals in sediments leads to existence of five categories including exchangeable, bound to carbonates (acid-soluble), bound to Fe-Mn oxides (reducible), bound to organic matter bond (oxidazable) and residual fraction (silicate). These categories have different behaviour with respect to remoblization under changing environment conditions. 


\section{MATERIALS AND METHODS}

\section{Sample locations and collection}

Sediment samples were collected from 16 different locations of the Karra River, Hetauda Nepal. The sampling locations were divided in three parts namely in upstream (US1 and US2), industrial belt (IB1 to IB12) and downstream (DS1 and DS2) of the Karra River. Sediment samples were collected in the month of May, 2007. Sediment samples were collected manually with the help of stainless steel scraper and spatula where flow was low. Three random samples were taken from each site, which were homogenized and composite samples were stored in plastic bag with zip lock.

\section{Sample processing}

The sediment samples were immediately sealed and stored at $4^{\circ} \mathrm{C}$ until reaching at laboratory. At the laboratory, sediment samples were first screened through a 1-mm sieve to remove large particles. The samples were airdried and subsequently kept in an oven at $65^{\circ} \mathrm{C}$ for $6 \mathrm{~h}$ for removal of water contents associate with the sediments. The dried samples were then ground in an agate mortar. The particles with size less than $63 \mu \mathrm{m}$ were collected. The $<63 \mu \mathrm{m}$ fraction also is important because it is the most chemically active fraction of sediment (Horowitz, 1991).

\section{Heavy metal fractionation}

The sediment samples were divided into two parts. One part was analyzed for heavy metal fraction and other analyzed for total heavy metals. The forms of heavy metals in the sediments were divided into the following fractions: (I) Fraction 1- exchangeable. One gram sediment sample was extracted with $1 \mathrm{M} \mathrm{MgCl}_{2}(\mathrm{pH} 7.0)$ at a solid to solution ratio of $1: 8$, with continuous agitations for $1 \mathrm{~h}$ at room temperature; (II) Fraction 11- bound to carbonate. The residue from step (1) was extracted with $1 \mathrm{M}$ NAOAc (adjusted pH 5.0 with Acetic acid) at a solid to solution ratio of $1: 8$. The mixture was agitated for five hours; (3) Fraction (III)-bound to iron and manganese oxides. The residue from (2) was extracted with $0.04 \mathrm{M}$ $\mathrm{NH}_{2} \mathrm{OH} . \mathrm{HCl}$ in $25 \%(\mathrm{v} / \mathrm{v}) \mathrm{HOAc}$ (initial $\mathrm{pH} 2.0$ and a solid to solution ratio of 1:20) with agitation for 6 hours; (4) Fraction IV- bound to organic matter/sulfide.

The residue obtained from step (3), $3 \mathrm{ml}$ of $0.02 \mathrm{M} \mathrm{HNO}_{3}$ and $5 \mathrm{ml}$ of $30 \% \mathrm{H}_{2} \mathrm{O}_{2}$ were added and $\mathrm{pH}$ adjusted to $\mathrm{pH} 2.0$ with $\mathrm{HNO}_{3}$. The solution was agitated at $96^{\circ} \mathrm{C}$ for 2 hours and $3 \mathrm{ml}$ of $30 \% \mathrm{H}_{2} \mathrm{O}_{2}\left(\mathrm{pH} 2\right.$ with $\mathrm{HNO}_{3}$ ) was added and sample was again agitated for 3 hours. After cooling, $5 \mathrm{ml}$ of $3.2 \mathrm{M}$ ammonium acetate in 20 $\%(\mathrm{v} / \mathrm{v}) \mathrm{HNO}_{3}$ was added. The sample was diluted to 20 $\mathrm{ml}$ and agitated continuously for 30 minutes. After each successive extraction, the supernatant was separated by centrifuging $7000 \mathrm{rpm}$ for 30 minute. The supernatant was further separated using a pipette filtered through a 0.45 micron filter paper (What man cellulose nitrate membrane filters). The filtrate obtained in each step of the extraction was analyzed for heavy metals. (5) Fraction $\mathrm{V}$ - residual fraction. The residue from (4) was digested with $\mathrm{HF} / \mathrm{HNO}_{3} / \mathrm{HClO}_{4}$ mixture. $100 \mathrm{mg}$ of residue was taken in a Teflon beaker and $20 \mathrm{ml}$ of acid mixture of $\mathrm{HF}, \mathrm{HNO}_{3}$ and $\mathrm{HClO}_{4}$ (in the ratio 7:3:1) was added. The Teflon beaker was placed in bomb digestion unit and heated $120^{\circ} \mathrm{C}$ for 2 hours.

\section{Metal extraction}

Total metals were extracted from sediment using an acid digestion. Fresh sample, $1.0 \mathrm{gm}$, was digested with 20 $\mathrm{ml}$ of acid mixture of $\mathrm{HF}, \mathrm{HNO}_{3}$ and $\mathrm{HClO}_{4}$ (in the ratio 7:3:1) in bomb digestion unit for $2 \mathrm{~h}$ at $120^{\circ} \mathrm{C}$.

\section{Metal analysis}

Metal ion concentrations in different extracts were determined by Shimadzu Atomic Absorption spectrophotometer (model AA-6000) using air-acetylene flame. Three replicate were run for each sample for metal analysis and instrument was recalibrated after every 15 samples. Blank was included in each batch of analysis. Calibration standards were regularly performed to evaluate the accuracy of analytical methods. All reagents were analytical grade. All glass ware used for experiments were first soaked in $15 \% \mathrm{HNO}_{3}(\mathrm{v} / \mathrm{v})$ for 24 hrs and rinsed with De-ionized water. De-ionized water used in each step of the experiment was obtained from Millipore machine $(18.3 \mathrm{M} \Omega \mathrm{cm}$ resistivity). The study established the identity between the sum of five metal fractions and the total metal to assure the precision in analyzing metal speciation in sediment.

\section{RESULTS AND DISCUSSION}

\section{Metal distribution}

The results of present study indicate that residual fraction is the most dominant fraction for all the metals. However, in most sites of the industrial belt, a significant proportion of metal was associated with the non-residual fraction. This indicates influence of anthropogenic activities on the riverine ecosystem.

Chromium: Fractional distribution of chromium indicates that major portion is bound to residual fraction at the most of the sites. Only negligible amount (4.55 to $6.91 \%$ ) of $\mathrm{Cr}$ released from non residual fraction and $95 \%$ in residual fraction in the upstream of the Karra (Fig.1). The fraction obtained by exchangeable and bound to carbonate, which are considered as weakly bound and easily available in the aqueous phase which is easily bioavailable (Gibbs, 1997). But upstream of the Karra River these two phases 
was found to be less. The high concentration of metal present in inert phase (residual) being detrital and lattice origin which can be taken as natural sources (Salomons and Forstner, 1984). So from these sites mobility and bioavailability is negligible because there is less human interference. The chromium content (total) within the sediment fraction varies from $13.23-3942.31 \mathrm{mg} /$ $\mathrm{kg}$ (industrial belt) in Table 2. A significant amount of $\mathrm{Cr}$ was associated with two fractions (reducible and oxidazable fraction) at site IB11 $(1282.48 \mathrm{mg} / \mathrm{kg}$ and 164.78 , respectively) and site $\mathrm{IB} 12(1986.43 \mathrm{mg} / \mathrm{kg}$ and $1925.40 \mathrm{mg} / \mathrm{kg}$, respectively) of the total extraction steps $1534.93 \mathrm{mg} / \mathrm{kg}$ and $3942.31 \mathrm{mg} / \mathrm{kg}$, respectively (Table 2). The high amount of $\mathrm{Cr}$ in the Fe-Mn oxides and organic phase may be due to scavenging effect and may provide a sink for heavy metals. The release of the metals from the matrix is most likely to be affected by redox potential and $\mathrm{pH}$. Anomalous results have been found at sites IB 11 and IB12. The sum of these two fractions contained more than 94.29 and $99.23 \%$ of the total amount of $\mathrm{Cr}$ at sites IB11 and IB12, respectively. However, a smaller percentage is also associated with residual fraction (Fig.1). Chromium has the capacity to form complexes with organic matter, thus it is mobile in the solution phase (Singh et al. 2003). This fraction indicates dominance of anthropogenic sources through leather industrial effluents. The speciation scheme of the
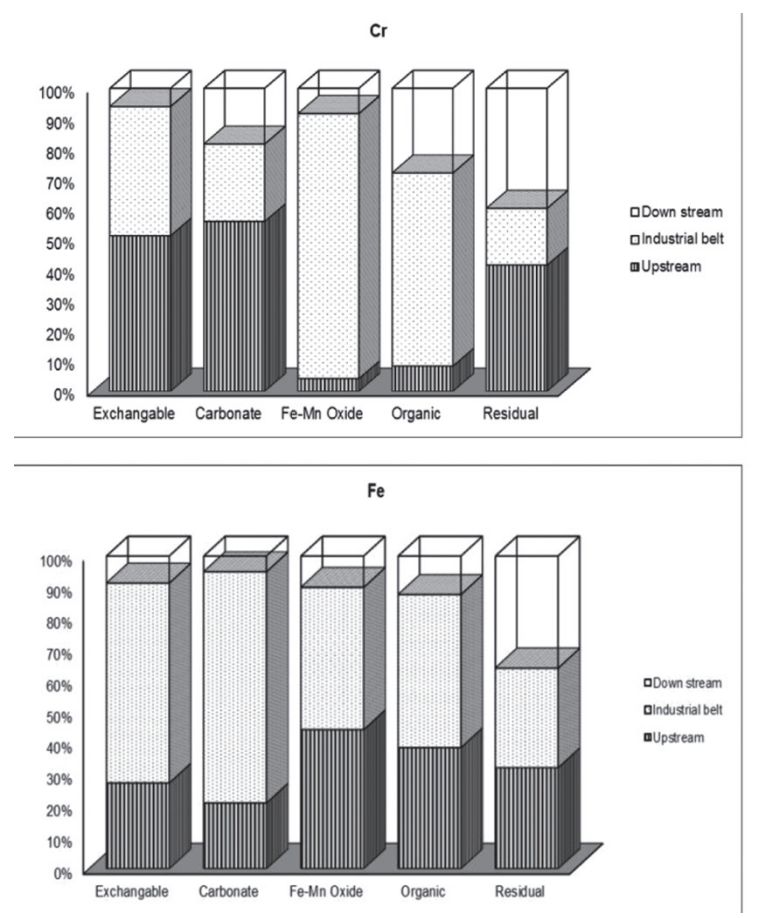

present study indicates its dominant presence with the oxidazable and reducible fraction of the sediment which is previously reported by Jain et al. 2008 and GalvezCloutier \&Dube (1998). In the downstream of the Karra River, residual fraction is found to be higher than other fractions (Fig.1). Cr concentration is found to be high in the residual fraction inferring less risk to the environment.

Manganese: Fractional distribution of Mn was mostly bound to organic and residual fraction at the upstream of the Karra River. Significant amount of Mn was found in all the five fractions, as observed by other researchers (Morillo et al. 2004; Jain et al. 2007). A significant amount of Mn was found in the acid soluble fraction in the industrial belt. In this fraction, weakly bound $\mathrm{Mn}$ retained on sediment surface by relatively weak electrostatic interactions may be released by ionexchange processes. In addition, a significant amount of Mn was detected in the reducible fraction, in which Mn exists as oxides and may be released if the sediment is subjected to more reducing conditions (Panda et al. 1995). A considerable portion of organic fraction was found, which dissociates to Mn-carbonate phase (Tessier et al. 1979). A large portion of reducible fraction was found in the downstream of the Karra River (Fig.1). The result indicates that considerable amount of Mn may be released into environment if conditions become more acidic (Peng et al. 2004).

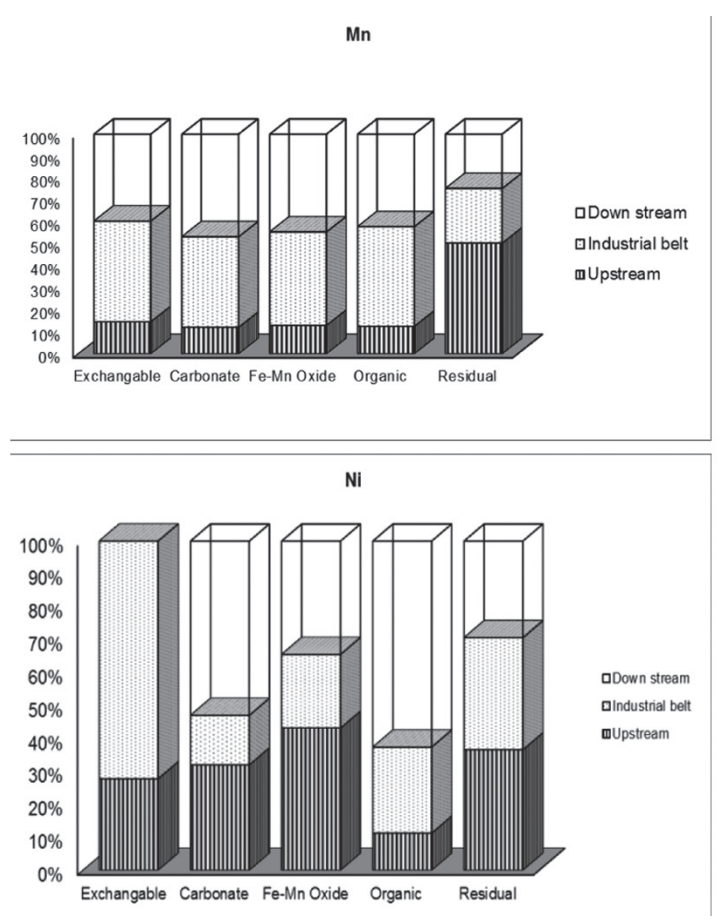

Fig.1 Results of the percentage distribution of $\mathrm{Cr}, \mathrm{Mn}, \mathrm{Fe}$ and $\mathrm{Ni}$ in the five extracted phases in sediments from the Karra River. 
Iron: $\mathrm{Fe}$ is the most abundant metal in all sediments because it is one of the most common elements in the Earth's Crust. The analysis of the distribution of $\mathrm{Fe}$ showed that most of it is associated with the residual phase (Fig.1). The remaining fractions of $\mathrm{Fe}$ were distributed among the reducible and the oxidazable phases. The percentage of $\mathrm{Fe}$ in these two fractions was, however, variable. The variability probably results from competition between $\mathrm{Fe}$ organic complexes and hydrous Fe oxide forms. A negligible amount of $\mathrm{Fe}$ was found in the exchangeable and carbonate fraction compared to the total concentration. Similar results were reported by Tuzen (2003), Yuan et al. (2004) and Jain et al. (2008). Higher amount of $\mathrm{Fe}$ associated with residual fraction characterizes stable compounds in sediments.

Nickel: The dominant portion of $\mathrm{Ni}$ was found in the residual fraction in samples from all the sites (Fig.1). These results are consistent with the observations of Gupta and Chen (1975), Tessier et al. (1979), Glosinska et al. (2005), this indicates that majority of $\mathrm{Ni}$ in sediments is detrital in nature. In the industrial belt and downstream, significant concentration of $\mathrm{Ni}$ was found as exchangeable, residual and organic fractions. These fractions are easily mobile in environmental conditions like low $\mathrm{pH}$ and low Eh conditions.

\section{Correlation}

Correlation coefficients among different metals are shown in Table 1. Correlation coefficients were found to be higher than 0.7 for $\mathrm{Ni}-\mathrm{Cr}$ and 0.45 for $\mathrm{Fe}-\mathrm{Mn}$ (Table 1). High correlation coefficient between different metals means their common sources and identical behavior during transport. The absence of strong correlation among other metals suggests that the concentration of these metals are not controlled by a single factor, but a combination of geochemical support phase and their mixed association (Jain et al. 2005).

Table 1, Correlation among different metals in sediments

\begin{tabular}{lcccc}
\hline & $\mathbf{C r}$ & $\mathbf{M n}$ & $\mathbf{F e}$ & $\mathbf{N i}$ \\
$\mathrm{Cr}$ & 1 & & & \\
$\mathrm{Mn}$ & -0.34 & 1 & & \\
$\mathrm{Fe}$ & -0.13 & 0.45 & 1 & \\
$\mathrm{Ni}$ & $0.73^{*}$ & -0.14 & -0.14 & 1 \\
\hline
\end{tabular}

Significant at $* p<0.05$

\section{Recovery of metal}

The accuracy of the sequential extraction procedure, recovery values $(\%)$ were calculated by comparing the sum of five- steps sequential extraction procedure (exchangeable, carbonate, reducible, organic and residue) with the total metal concentration. The recovery of the sequential extraction was calculated as follows:

Results showed that the sequential extraction procedure is repeatable and reliable, with recoveries for all heavy metals ranging from 83.26 to $109.07 \%$ (Table 2 and3).

Table 2. Average percentage of each fraction in $\mathbf{1 6}$ sampling sites of the Karra River

\begin{tabular}{|c|c|c|c|c|c|c|}
\hline \multirow{2}{*}{$\begin{array}{l}\text { Sample } \\
\text { sites }\end{array}$} & \multicolumn{3}{|c|}{$\mathrm{Cr}$} & \multicolumn{3}{|c|}{ Mn } \\
\hline & $\begin{array}{c}\text { Sum of the extraction steps } \\
\text { of metal }(\mathrm{mg} / \mathrm{kg})\end{array}$ & $\begin{array}{l}\text { Total metal } \\
(\mathrm{mg} / \mathrm{kg})\end{array}$ & $\begin{array}{l}\text { Recovery } \\
\%\end{array}$ & $\begin{array}{l}\text { Sum of the extraction } \\
\text { steps of metal }(\mathrm{mg} / \mathrm{kg})\end{array}$ & $\begin{array}{l}\text { Total metal } \\
(\mathrm{mg} / \mathrm{kg})\end{array}$ & $\begin{array}{c}\text { Recovery } \\
\%\end{array}$ \\
\hline US1 & 23.38 & 21.72 & 107.65 & 182.39 & 205.629 & 88.70 \\
\hline US2 & 39.6 & 47.56 & 83.26 & 171.1 & 189.21 & 90.43 \\
\hline IB1 & 13.23 & 12.90 & 102.56 & 251.08 & 280.188 & 89.61 \\
\hline IB2 & 120.73 & 110.80 & 108.96 & 399.81 & 389.79 & 102.57 \\
\hline IB3 & 65.12 & 75.63 & 86.10 & 368.06 & 407.86 & 90.24 \\
\hline IB4 & 73.75 & 81.13 & 90.91 & 99.09 & 111.99 & 88.47 \\
\hline IB5 & 72.65 & 70.92 & 102.45 & 182.13 & 210.34 & 86.59 \\
\hline IB6 & 76.44 & 70.08 & 109.07 & 216.1 & 239.71 & 90.15 \\
\hline IB7 & 144.57 & 149.03 & 97.01 & 92.22 & 100.44 & 91.81 \\
\hline IB8 & 116.58 & 130.24 & 89.51 & 80.31 & 90.341 & 88.90 \\
\hline IB9 & 38.06 & 40.87 & 93.13 & 54.75 & 52.22 & 104.83 \\
\hline IB10 & 77.48 & 87.23 & 88.82 & 59.74 & 57.71 & 103.51 \\
\hline IB11 & 1534.93 & 1697.42 & 90.43 & 79.05 & 87.955 & 89.88 \\
\hline IB12 & 3942.31 & 4339.54 & 90.85 & 81.5 & 88.65 & 91.93 \\
\hline DS1 & 92.44 & 90.68 & 101.94 & 371.76 & 411.93 & 90.25 \\
\hline DS2 & 28.01 & 32.81 & 85.37 & 314.94 & 350.43 & 89.87 \\
\hline
\end{tabular}


Table 3. Average percentage of each fraction in $\mathbf{1 6}$ sampling sites of the Karra River

\begin{tabular}{|c|c|c|c|c|c|c|}
\hline \multirow{2}{*}{$\begin{array}{l}\text { Sample } \\
\text { sites }\end{array}$} & \multicolumn{3}{|c|}{$\mathrm{Fe}$} & \multicolumn{3}{|c|}{$\mathbf{N i}$} \\
\hline & $\begin{array}{l}\text { Sum of the extraction } \\
\text { steps of metal }(\mathrm{mg} / \mathrm{kg})\end{array}$ & $\begin{array}{l}\text { Total metal } \\
(\mathrm{mg} / \mathrm{kg})\end{array}$ & $\begin{array}{c}\text { Recovery } \\
\%\end{array}$ & $\begin{array}{c}\text { Sum of the extraction } \\
\text { steps of metal }(\mathrm{mg} / \mathrm{kg})\end{array}$ & $\begin{array}{l}\text { Total metal } \\
(\mathrm{mg} / \mathrm{kg})\end{array}$ & $\begin{array}{c}\text { Recovery } \\
\%\end{array}$ \\
\hline US1 & 2879.12 & 2760.03 & 104.31 & 27.9 & 31.70 & 88.01 \\
\hline US2 & 9276.22 & 9090.84 & 102.04 & 20.45 & 19.50 & 104.90 \\
\hline IB1 & 8055.03 & 8857.53 & 90.94 & 67.53 & 66.28 & 101.88 \\
\hline IB2 & 19066.72 & 21978.39 & 86.75 & 73.18 & 71.50 & 102.35 \\
\hline IB3 & 9592.46 & 10561.71 & 90.82 & 90.58 & 100.64 & 90.01 \\
\hline IB4 & 4933.81 & 4827.19 & 102.21 & 27.55 & 34.31 & 80.31 \\
\hline IB5 & 7199.01 & 7948.91 & 90.57 & 77.04 & 89.74 & 85.84 \\
\hline IB6 & 10482.89 & 11542.18 & 90.82 & 28.92 & 34.81 & 83.07 \\
\hline IB7 & 10475.68 & 10063.25 & 104.10 & 83.87 & 92.26 & 90.91 \\
\hline IB8 & 5923.70 & 6526.07 & 90.77 & 50.5 & 58.55 & 86.25 \\
\hline IB9 & 2679.30 & 2967.23 & 90.30 & 33.34 & 31.67 & 105.26 \\
\hline IB10 & 3963.27 & 4167.60 & 95.10 & 30.78 & 32.86 & 93.68 \\
\hline IB11 & 10044.19 & 11399.61 & 88.11 & 56.21 & 63.83 & 88.06 \\
\hline IB12 & 5634.15 & 6199.57 & 90.88 & 169.76 & 180.74 & 93.93 \\
\hline DS1 & 27685.08 & 30459.59 & 90.89 & 43.41 & 40.75 & 106.52 \\
\hline DS2 & 29461.83 & 32423.01 & 90.87 & 58.58 & 64.44 & 90.91 \\
\hline
\end{tabular}

\section{CONCLUSIONS}

In natural water bodies, trace metals undergo numerous changes during their transport due to dissolution, precipitation and sorption phenomena. Trace element concentrations of river basins depend on not only industrial and household waste inputs but also on the geochemical composition of the area. The sequential extraction method applied to sediments, sample offers a more appropriate valuation of the potential environmental hazards by heavy metals. Degree of mobility and bio-availability of heavy metals depends upon various geochemical forms, and therefore, this approach is very useful for site assessment and risk analysis. Metals bound to different phases will behave differently in the sedimentary environment, and thus have different potentials for remobilization and for uptake by biota.

The bed sediments of the Karra River were studied to obtain information, distribution, speciation, and sources of heavy metals. High concentrations of $\mathrm{Cr}$ are thought to have resulted from anthropogenic influences, practically from leather industry (Hetauda industrial district) and are found to present a pollution risk. This indicates that the anthropogenic effects were dominant in the increase of heavy metal contents in the Karra River. Mn enrichment in river sediments has an exchangeable character in some of the sites of industrial belt and represents pollution potential in this river. This result shows that Mn pollution might be originated from industry. Fe concentrations in the Karra River depend on the geochemical structure. The residual fraction was the most abundant fraction for
Fe concentration in the sediment studied. In the upstream and downstream of the Karra River, high concentration of metal present are in inert phase (residual), being detrital and of lattice origin. The low concentration of the exchangeable and carbonate fraction suggests poor elemental availability to the bottom-dwelling organisms in this environment. However, in most of the sites in the industrial belt, a significant proportion of metal was associated with the non-residual fraction. As in the $\mathrm{Ni}$ and Co speciation study, this metal is found bound to silicates and less concentration in non residual fraction

\section{ACKNOWLEDGEMENTS}

The Author gratefully acknowledge the technical assistance from Department of Environmental Science, University of Delhi, Delhi for AAS analyses

\section{REFERENCES}

Chapman, P.M. and Wang, F.Y.1999. Appropriate applications of sediments quality values for metals and metalloids. Environmental Science and Technology 33:3937-3941.

Chatterjee, M., Silva Filho, E.V., Sarkar, S.K.., Sella, S.M., Bhattacharya, A., Satpathy, K..K.., Prasad, M.V.R., Chakraborty S., and Bhattacharya, B.D. 2007. Distribution and possible source of trace elements in the sediment cores of a tropical macrotidal estuary and their ecotoxicological significance. Environmental International 33: 346-356. 
Demirak, A., Yilmaz, A.L. and Ozdemir, T. N. 2006. Heavy metal in water, sediment and tissues of Leuciscus cephalus from a stream in southwestern Turkey. Chemosphere 63:1451-1438.

Dessai, V.G.D and Nayak, G.N. 2009. Distribution and speciation of selected metals in surface sediments, from the tropical uari estuary, central west coast of India. Environmental Monitoring and Assessment 158:117-137.

Galvez-Cloutier, R and Dube, J.S. 1998. An evaluation of fresh water sediments contamination: the Lachine Canal sediments case, Montreal, Canada: Part II. Heavy metal particulate speciation study. Water, Air and Soil Pollution 102:281-302

Glosinska, G., Sobczynski, T., Boszke, L., Bierla and K., Siepak, J. 2005., Fractionation of some heavy metals in bottom sediments from the middle Odra River ( Germany / Poland). Polish, Journal of Enironmental studies 14 (3): 305-317.

Gibbs, R.J. 1977. Transport phases of transition metals in Amazon and Yukon rivers. Geological Society of American bulletin 88: 829-843.

Gupta, S.K. and Chen,K.Y., 1975. Partition of trace metals in selective chemical fraction of nearshore sediments. Journal of Environmental Letters 10: 129-158.

Horowitz, A.J.1991. A primer on sediment- trace element chemistry $\left(2^{\text {nd }} e d\right)$. Lewis Publishers, Chelsea, 136p

Howard, J.L. and Shu, J. 1996. Sequential extraction analysis of heavy metals using a chelating agent (NTA) to counteract resorption. Environmental Pollution 91: 89-96.

Jain, C.K., Singhal., D.C. and Sharma, M.K. 2005. Metal pollution assessment of sediment and water in river Hindon, India. Environmental Monitoring and Assessment 105: 193-207.

Jain, C.K., Malik, D.S. and Yadav, R. 2007. Metal fraction study on bed sediment of Lake Nainital, Uttaranchal, India. Environmental Monitoring and Assessment 130: 129-139.

Jain, C.K., Gupta, H., Chakrapani, G.J., 2008. Enrichment and fractionation of heavy metals in bed sediments of River Narmada, India. Environmental Monitoring and Assessment 141: 35-47.

Jalali, M. and Khanlari, Z.V. 2008. Environmental contamination of $\mathrm{Zn}, \mathrm{Cd}, \mathrm{Ni}, \mathrm{Cu}$, and $\mathrm{Pb}$ from industrial areas in Hamadan Province, western Iran. Environmental Geology 55:1537-1543.

Kersten, M. and Forstner, U., 1986. Chemical fraction of heavy metals in anoxic estuarine and coastal sediments. Water Science and Technology 18: 121130.
Loska, K. and Wiechula, D. 2003. Application of principal component analysis for the estimation of source heavy metal contamination in surface sediments from Rybnik Reservoir. Chemosphere 51:723-733

Morillo, J., Usero, J. and Garcia, I. 2004. Heavy metals distribution in marine sediments from the southwest coast of Spain. Chemosphere 55: 431-442.

Panda, D., Subramanian, V. and Panigraphy, R. C. 1995. Geochemical fractionation of heavy metals in Chilka Lake (east coast of India)- a tropical coastal lagoon. Environmental Geology 26: 199-210.

Peng, S. H., Wang, W. X., Li, X. D. and Yen, Y. F. 2004. Metal partitioning in river sediments measured by sequential extraction and biomimetic approaches. Chemosphere 57: 839-851.

Rath, P., Panda, U.C., Bhatta, D. and Sahu, K.C. 2009. Use of sequential leaching, mineralogy, morphology and multivariate statistical technique for quantifying metal pollution in highly polluted aquatic sediments-a case study: Brahmani and Nandira Rivers. India Journal of Hazardous Materials 163: 632-644.

Salomons, W. and Forstner, U. 1984. Metals in Hydrocycle. Springer, Verlag, New York, 349p

Singh, K.P., Mohan, D., Singh, V.K. and Malik, A. 2005. Studies on distribution and fractionation of heavy metalsin Gomti river sediments - a tributary of the Ganges, India. Journal of Hydrology 312: 14-17.

Singh, M., Muller, G.and Singh, I.B. 2003. Geogenic distribution and baseline concnetraion of heavy metals in sediments of Ganges River, India. Joiurnal of Geochemical Exploraion 80: 1-17

Sutherland, R.A. and Tack, F.M.G. 2007. Sequential extraction of lead from grain size fractionated river sediments using the optimized BCR Procedure. Water Air Soil Pollution 84: 269-284.

Tessier, A., Cambell, P.G.C. and Bisson, M.X. 1979. Sequential extraction procedure for the speciation of particulate trace metals. Analytical Chemistry 51: 844-851.

Tuzen, M. 2003. Determination of trace metals in Yesilimak sediments in Tokat, Turkey using sequential extraction procedure. Microchemical journal 74: 105-110.

Yuan, C., Shi, J., He, B., Liu, J., Liang, L. and Jiang, G. 2004. Speciation of heavy metals in marine sediments from the east China Sea by ICP-MS with sequential extraction, Environmental International 30: 769-783. 